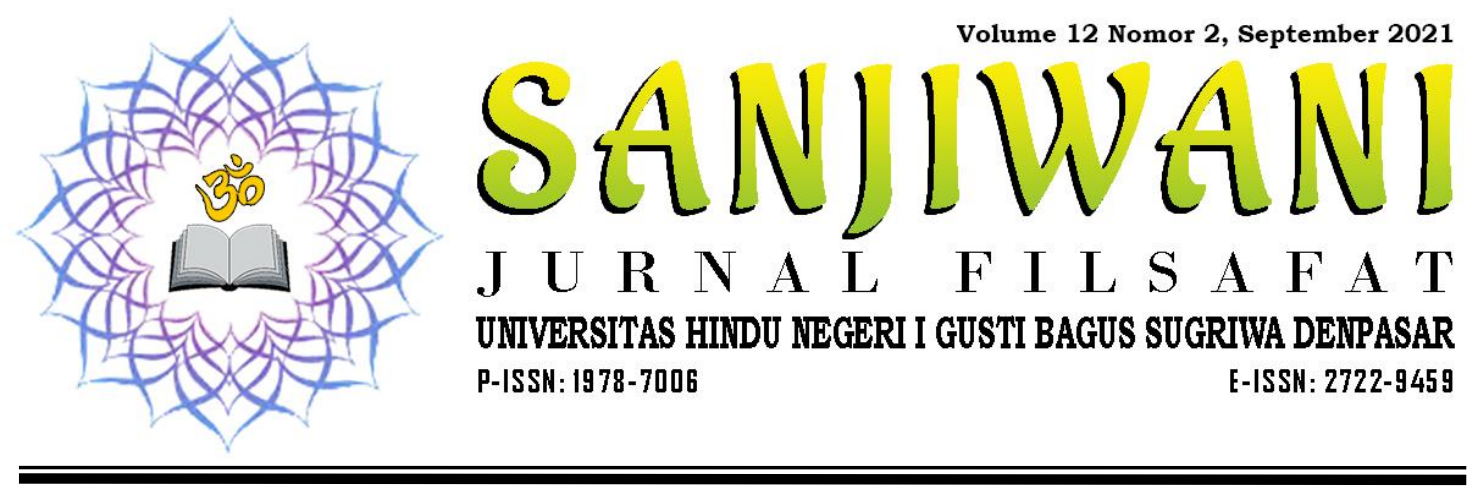

\title{
Filosofi Tradisi Ruwatan dalam Ritual Hindu Bali (Analisis Wayang Kulit Sudhamala dan Sapuhleger)
}

\author{
I Ketut Muada \\ Universitas PGRI Mahadewa Indonesia \\ muadaketut@gmail.com
}

\begin{tabular}{|ll|}
\hline Keywords: & ABSTRACT \\
\hline Function; & The ritual of ruwatan in Balinese Hindu society basically \\
Meaning; & removes or cleanses oneselffrom dirt, which is practiced almost the \\
Philosophy of & same in general throughout Bali. In ruwatan using wayang kulti \\
Ruwatan & media, there are two types of performing arts which contain the \\
& function and meaning of ruwatan, such as; puppet show gedog \\
& (weak puppet) and puppet show Peteng. The source of the \\
& pangruwatan play presented by the puppeteers refers to the \\
& ruwatan standard although in practice it changes according to the \\
& situation and conditions of the performance itself. The play taken \\
& in the wayang gedog is Sudhamala, while in the shadow puppet \\
& show at night it is Sapuhleger. Ruwatan or in Java known as \\
& murwakala has a broad meaning not only a literary work and \\
& pakeliran but its function and philosophy, it turns out that it refers \\
& to the micro and macro essence of humans as being creative, \\
& intellect and intention. This research specifically reveals problems \\
& regarding; the form of the play, the function and meaning of \\
& spiritual philosophy, as well as the role of government in relation \\
& to ritual rituals. In revealing this, the researchers used qualitative \\
& methods, as well as several theories that complement this research. \\
\hline
\end{tabular}

\begin{tabular}{|ll|}
\hline Kata Kunci & ABSTRAK \\
\hline Fungsi; Makna; & \multicolumn{1}{c|}{ Ritual ruwatan pada masyarakat Hindu Bali pada } \\
dan Filosofi & dasarnya membuang atau pembersihan diri dari kotoran, \\
Ruwatan & yang pelaksanaannya hampir sama pada umumnya \\
& diseluruh Bali. Dalam ruwatan dengan media wayang kulit, \\
& ada dua jenis seni pertunjukan yang mengandung fungsi dan \\
& makna ruwatan seperti; pertunjukan wayang gedog (wayang \\
& lemah) dan pertunjukan wayang Peteng. Sumber lakon \\
& pangruwatan yang disajikan oleh para dalang mengacu pada \\
\hline
\end{tabular}




pakem ruwatan walaupun dalam pelaksanaannya berubah
menurut situasi dan kondisi pertunjukan itu sendiri. Lakon
yang diambil dalam wayang gedog adalah Sudhamala
sedangkan, dalam pertunjukan wayang kulit pada malam
hari adalah Sapuhleger. Ruwatan atau di Jawa dikenal
dengan murwakala mempunyai makna yang luas tidak
hanya sebuah karya sastra dan pakeliran akan tetapi fungsi
dan filosofinya, ternyata mengacu pada esensi mikro dan
makro manusia sebagai insan yang berdaya cipta, budi dan
karsa. Penelitian ini khusus mengungkap permasalahan
tentang; bentuk lakon, fungsi dan makna filosopi ruatan,
serta peranan pemerintah terkait ritual ruatan. Dalam
mengungkap hal tersebut peneliti memakai metode
kualitatif, serta beberapa teori-teori yang melengkapi
penelitian ini.

\section{PENDAHULUAN}

Dijaman era globalisasi sekarang ini, akibat pengaruh penalaran dan semakin mantap keyakinannya terhadap agama yang dianggap modern, ada sebagian masyarakat tidak perlu lagi menyelenggarakan upacara ruwatan. Bahkan ada segolongan masyarakat yang menganggapnya sebagai peristiwa yang tidak rasional. Namun, dalam kenyataanya tradisi ruwatan itu pada berbagai masyarakat Hindu Bali masih bertahan sampai sekarang. Tidak hanya terbatas dikalangan masyarakat pedesaan, tetapi dikalangan masyarakat kota dan bahkan yang tergolong kelompok intelektualpun dewasa ini turut mengikuti tradisi ruwatan itu dengan serius. Dalam menyelenggarakan upacara ruwatan dengan berbagai macam sesaji yang sangat rumit oleh kalangan orang berada diupayakan selengkap mungkin. Kenyataan itu sebagai bukti bahwa dalam kehidupan masyarakat Hindu Bali, upacara ruwatan masih memilki fungsi yang tidak dapat dikesampingan. Istilah ruwatan berasal dari kata "Ruwat" yang berarti pembersihan dari kotoran, kutukan atau kemalangan (Subalinata, 1985:11).

Upacara ruawatan dilakukan oleh masyarakat Hindu Bali dengan tujuan untuk membebaskan diri dari malapetaka yang diperkirakan akan menimpa salah satu keluarganya, yang disyaratkan dalam kelahirannya, sakit berkepanjangan, prilaku diluar batas yang bikin kesal keluarga, dan anak tersebut selalu sial dalam kreativitasnya sehari-hari. Orang-orang tersebut dikatagorikan harus diruawat dengan pertunjukan wayang kulit sebagai wayang ruwatan dengan cerita khas ruwatan yaitu Sudhamala dan Sapuhleger. Cara seperti ini sebagai upaya pembebasan terhadap hal-hal yang buruk yang akan menimpanya. Menurut masyarakat Hindu Bali, jika ruawatan itu tidak dilaksanakan maka orang yang bersangkutan akan dimangsa oleh Bhatara Kala. Artinya orang yang termasuk katagori kotor/sukerta (Istilah Jawa) tetapi tidak diruwat akan mengalami nasib sial dalam hidupnya.

Secara umum ruwatan di Bali merupakan suatu fenomena kehidupan sosial dimana manusia mulai sadar dengan kekutan alam yang besar di luar dirinya 
yang dapat mempengaruhi kehidupanya. Manusia mulai ingin mengadakan kontak dengan kekuatan tersebut untuk memperoleh perlindungan dan pembebasan dari berbagai bahaya. Peranan pemerintah di Bali sudah menunjukan keseriusannya dalam menyelamatkan masyarakat yang di katagori kotor/sukerta, dengan melaksanakan ruwatan masal. Hal ini dimaksudkan, agar pengiritan biaya ruwatan dengan mengelar seni pertunjukan wayang ruwatan Sapuhleger.

\section{METODE}

Bentuk penelitian ini adalah seni pertunjukan yang kontekstual, namun menggunakan pendekatan secara ekletik yaitu pendekatan berbaga faktor secara komolatif. Penelitian ini bersifat menerangkan, menguji hipotesis-hipotesis tentang adanya hubungan kausalitas berbagai variabel yang diteliti. Berdasarkan sifat-sifat penelitian di atas, metode kualitatif dianggap telah tepat digunakan sebagai pedoman atau prinsif penelitian, melalui pengumpulan data, proses analisis sampai memberikan kesimpulan sebuah penelitian.

\section{PEMBAHASAN}

\subsection{Bentuk Lakon Ruwatan Wayang Kulit di Bali}

Kerangka bentuk pengruwatan dengan media pertunjukan wayang kulit jenisnya ada 2 pertunjukan diantaranya;(1) Ruwatan Sudhamala, pelaksanaannya pada siang hari, wayang ruwatan ini sering di Bali disebut wayang lemah/wayang gedog. Wayang lemah berasal dari kata "lemah" yang artinya siang hari. Ruwatan wayang lemah berbeda dengan ruwatan yang dilaksanakan pada ruwatan malam hari. Bentuk pertunjukan wayang ruwatan lemah secara garis besar yaitu: (a) Tidak menggunakan kelir/kain putih, melainkan memakai tali benang, (b) Pembatas sebelah kiri dan kanan sebagai pengikat tali benang adalah ranting kayu dadap, (c) 1 batang pohon pisang berfungsi sebagai penancab wayang, (d) Di sebelah dalang tepatnya diranting pohon dadap berisi uang kepeng 250 sebelah kanan, 250 kepeng sebelah kiri. (2) Ruwatan Sapuhleger, pelaksanaannya sebagian besar pementasan wayangnya pada malam hari dengan acuan lontar Siwagama, Kala tatwa, dan Siwa tatwa. Aparatus pementasannya sangat besar, khusus anak yang lahir pada wuku wayang sesuai kelender Bali.

\subsection{Lakon Sudhamala Ruwatan Wayang Lemah/Gedog}

Lontar Siwagama dan Gaguritan Empehan Lembu Petak menceritakan Hyang Siwa menyuruh istrinya Dewi Uma untuk mencari obat ke mercapada/ dunia manusia. Hyang Siwa berpura-pura sakit hanya bermaksud menguji kesetian seorang Dewi Uma. Tidak membuang waktu, Dewi Umapun berangkat ke alam manusia. Keberangkatan Sang Dewi rupanya di ikuti oleh Hyang Siwa dengan berubah wujud menjadi seorang gembala sapi. Perjalanan Dewi Uma mengarungi lautan, gunung, sawah, dan sungai besar maupun kecil, lama tidak menemukan obat yang beliau inginkan. Suatu ketika, Dewi Uma berjalan-jalan di hutan yang sangat lebat sekali, disana ada seorang gembala sapi yang sedang duduk menunggu sapi-sapinya yang sedang makan rumput. Malihat sapi putih yang beliau cari-cari selama ini, akhirnya Dewi Uma menemui gembala sapi tersebut. 
Perbincangan Dewi Uma dengan Gembala sapi sangat alot, dari perkenalan, tujuan / maksud kedatangan hingga sebuah kesepakatan. Tujuan Dewi Uma ke hutan adalah mencari air susu sapi warna putih untuk obat suami yang sakit, karena air sapi putih tidak boleh dibeli dengan uang atau emas, akhirnya segala cara oleh Dewi Uma dilakukan agar mendapat air susu sapi berwarna putih. Sang gembala sapi membuat kesepakatan dengan Dewi Uma, jika ingin air susu sapi warna putih, Dewi Uma harus melayani sang gembala layaknya hubungan suami istri. Setelah hubungan tersebut selesai, Dewi Uma kembali ke Siwa loka dengan membawa air susu sapi untuk obat sang suami. Sedangkan gembala sapi tiada lain Hyang Siwa telah kembali duluan ke sorga agar rencana ini tidak diketahui oleh Dewi Uma.

Kedatangan Dewi Uma di sorga, disambut oleh Hyang Siwa bersama anaknya hyang Gana. Dialog antara ketiga dewa tersebutpun terjadi, ketika di tanya Dewi Uma tentang bagaimana cara mendapatkan air susu sapi berwarana putih, Dewi Uma sedikit berbohong. Kebohongan ini pada akhirnya kentara ketiga Hyang Siwa menyuruh Hyang Gana untuk menenung/melihat dengan sebenarnya melalui Panca Indranya Hyang Gana. Dewi Uma marah membakar ilmu tenung Hyang Gana ketika memberitahu kebenaran tersebut pada Hyang Siwa. Dewi Uma dikutuk menjadi rupa yang seram dengan nama Dewi Durga, tempat beliau di kuburan. Ditempat baru ini (Kuburan) Dewi Durga mempunyai 7 abdi diantaranya; I Rarung, I Lende Lendi, Mahesawedana, I Jaran guyang, Waksirsa, I dan Suatu hari Pandawa membuat ritual (Pitra Yadnya) akibat meninggalnya Raja Pandhu. Upacara/ritual Pandawa dirusak oleh abdi Dewi Durga yang menyebabkan Sri Krisna menyuruh Sang Sahdewa mendatangi kuburan. Kedatangan Sang Sahdewa sebagai penjelmaan Sanghyang Usadhadewa (Dewanya Dukun/balian) membuat Dewi Durga merasa dibersihkan dengan senjata Tebusala (tebas/tebus dan sala/mala) yang mengandung arti pembersihan kotoran/mala. Berdasarkan cerita/lakon tersebut darah Sang Dewi yang tumpah di tanah tumbuh menjadi bunga mitir, tulang menjadi pohon tebu sala, air susu menjadi pohon pisang sabha, dan kotorannya tumbuh menjadi pohon buah mengkudu, semua ini tidak diperbolehkan menjadi persembahan/sesajen para dewa-dewa (Dewa Yadnya). Dewi Durga akhirnya kembali kesorga dengan wujud Dewi Uma, sedangkan Sahdewa dianugrahkan mantra Sudhamala yang mengandung fungsi dan makna pembersihan lahir dan batin.

\subsection{Lakon Sapuhleger dalam Wayang Ruwatan di Bali}

Istilah sapuh leger berasal dari kata dasar "sapuh"dan"leger:"Dalam Kamus Bali-Indonesia, terdapat kata"sapuh" (alus mider) artinya alat untuk membersihkan; nyapuh artinya membersihkan; kesapuhan artinya dibersihkan; mesapuh-sapuh artinya melakukan pembersihan, kata leger sinonim dengan kata "lenget" yang artinya tercemar/kotor. Sapuh Leger secara harafiah berarti pembersihan atau penyucian dari keadaan yang tercemar atau kotor. Secara keseluruhan, Wayang sapuh leger adalah suatu drama ritual dengan serana pertunjukan wayang kulit yang bertujuan untuk membersihkan atau mencucikan diri seseorang akibat tercemar atau kotor secara rohani. 
Naskah Lontar Siwagama dan lontar Tantu Pagelaran, cukup jelas menyebutkan adanya pertunjukan wayang kulit lengkap dengan aparatusnya. Secara ekplisit lontar ini menyebutkan asal mula wayang ruwatan sesuai yawa mandala. Lontar ini menceritakan Dewa Kala mendapat kedudukan yang istimewa dalam kehidupan masyarakat Bali, karena lakon tersebut termasuk mitos yang diyakini dan dipercayainya. Menurut Peursen mengatakan bahwa, mitos adalah cerita yang memberikan pedoman dan arah tertentu kepada sekelompok orang, cerita yang mengandung simbol dan berkaitan pada hal-hal yang bersifat magis dan religius. Sejalan pendapapat diatas bahwa anak yang laih pada wuku wayang harus mengikuti kebiasaan-kebiasaan turun temurun dalam prilaku kehidupan sosial masyarakat Bali. Lakon sapuh leger adalah jenis cerita/lakon yang mengandung pasemon filosofik dan berkaitan dengan hal-hal yang bersifat magis. Jadi dengan demikian maka upacara/sajian sapuh leger merupakan paduan yang serasi antara materi dan serana, antara isi dan wadah.

Lakon Sapuh leger berawal dari kelahiran Dewa kala, ketiaka Hyang Siwa bersama Dewi Uma (Istrinya) berkunjung ketepi laut. Sesampainya di tepi laut, Hyang Siwa terpesona melihat kemolekan Dewi Uma pada saat busana sang istri diterpa angin laut. Paha Dewi Uma yang putih mulus mampu membangkitkan asmara Hyang Siwa. Karena tidak mampu menahan asmara, air Kama/nafsu Hyang Siwa (Kama salah) jatuh di samudra yang luas. Kedua dewa inipun kembali ke sorga namun, kama salah yang hanyut tersebut semakin hari, semakin bulan membesar dan bercahaya hingga para dewa di sorga tidak mampu merasakan panas cahaya yang ditimbulkan oleh benih Hyang Siwa tersebut. Atas perintah dan inisiatif para dewa-dewa, benih tersebut akhirnya di bombardir dengan senjata milik dewa masing-masing. Namun, benih salah tersebut semakin membesar hingga berwujud Raksasa. Raksasa besar tersebut mengamuk mencari jati diri, semua dewa yang menghalangi lari tunggang langgang. Melihat hal tersebut, Hyang Siwa menemui raksasa besar tersebut dan mengakui bahwa dia adalah anak Hyang Siwa. Pertemuan tersebut pada akhirnya raksasa tersebut di berinama Dewa Kala, di samping itu, Dewa Kala dianugrahkan tugas pokok salah satunya berhak memangsa yang lahir dalam wuku wayang (perhitungan dalam kalender Bali).

Adik Dewa Kala yang bernama Hyang Kumara tepat kelahirannya pada hari Sabtu Wuku Wayang(Tumpek Wayang) menjadi target santapan Dewa Kala. Suatu ketika Dewa Kala memohon ijin pada Hyang Siwa agar mengijinkan menyantap Hyang Komara namun, Hyang Siwa menggagalkan maksud tersebut karena adiknya masih kecil. Agar Hyang kumara terindar dari santapan Dewa Kala, akhirnya diberi ajian/mantra penunda dewasa. Karena setiap hari diminta untuk disantap, akhirnya Hyang Kumara lari kedunia manusia/ Mercapada. Di alam manusia ini Hyang Kumara berlari kesana kesini guna menghindari santapan Dewa Kala. Setiap objek yang dipakai tempat bersembunyi dikutuk oleh Dewa kala seperti tempat masak (bungut paon), membuang bambu yang tidak berisi bukunya/ruasnya, pohon kelapa dan sebagainya. Posisi sudah kepayahan akibat lari, Hyang Siwa mengadang perjalanan Dewa kala wujud seorang petani membajak sawah dengan menggunakan satu ekor lembu dan dikuti prempuan cantik, dengan maksud agar Hyang Kumara dapat istirahat 
sebentar. Dewa Kala disuruh menjawab pertanyaan Hyang Siwa. "Asta Padha, Sad Lungayan, Dwi Serenggi, Eka Banggo, muka enggul, catur Putuh, Sapta Loncanem". Pertanyaan Hyang Siwa tidak bisa dijawab mengakibatkan Dewa Kala merasa diolok-olok seraya lagi mengejar Hyang Kumara.

Pada suatu malam, disebuah pedesaan ada pertunjukan wayang kulit dengan upacara/ banten yang sangat lengkap. Di muka pertunjukan wayang disajikan upacara yang besar dengan berisi satu ekor babi guling, sanggah surya dibawahnya taur ayam brumbun, 2 sanggah tutuan samping kanan dan kiri kain putih yang membentang(kelir), dan pohon pisang beserta jantungnya sebagai alas menancabkan wayang ketika pertunjukan berlangsung. Dewa Kala yang sudah tahu Hyang kumara sudah duluan dihadapan dalang, merasa lapar ketika nonton wayang. Tidak ada basa-basi, Dewa Kala langsung menyantap babi guling dan di ikuti kala-kali anak buahnya. Upacara di hadapan wayang rusak, Ki dalang bertanya; wahai Dewa upacara ini tidak untukmu kenapa Dewa merusaknya?. Dari kesalahan ini Dewa Kala mohon maap pada Ki dalang dan sebagai gantinya Ki dalang dianugrahi melukat/menyucikan orang yang lahir pada wuku wayang, dengan catatan harus melalui pertunjukan wayang Sapuh Leger. Dewa Kala merasa puas dan pulang ke sorga, sedangkan Hyang Kumara akhirnya tertolong dengan sebuah ruwatan Sapuh leger.

\subsection{Fungsi Wayang Ruwatan Bagi Kehidupan Masyarakat Bali}

Fungsi kesenian bagi masyarakat Hindu Bali adalah salah satunya sebagai alat komonikasi untuk memperkuat keyakinan, nilai-nilai, norma-norma yang hidup dalam masyarakat. Secara universal dikaitkan pertama dan utama dan relegi, karena dalam relegi tertanam berbagai nilai dan norma yang membawa masyarakat kesuatu kemungkinan untuk berkomonikasi dengan hakekat tertinggi secara lebih tenang dan tepat. Fungsi kesenian khususnya seni pertunjukan, R.M.Soedarsono, seorang pakar seni pertunjukan tari, musik,dan teater mengutarakan tiga fungsi utama, yaitu: (1) Sarana upacara atau Ritual; (2) Hiburan pribadi; dan (3) Penyajian estetis. I Made Bandem juga mengamati fungsi kesenian khususnya wayang kulit yang di yakini oleh orang Bali memiliki arti dan makna sebagai: (1) Penggugah rasa indah dan kesenangan; (2) Memberi hiburan sehat; (3) Media komonikasi; (4) Persembahan simbolis; (5) Penyelenggaraan keserasian norma-norma masyarakat; (6) Pengukuhan institusi sosial dan upacara keagamaan; (7) Kontribusi terhadap kelangsungan dan stabilitas kebudayaan; (8) Pencipta integritas masyarakat.

Sebagai fungsi sosial efek dari suatu keyakinan adat yang berkaitan dengan ritual keagamaan. Pementasan wayang ruwatan sebagai ritual keagamaan, berfungsi untuk upacara manusa Yajna, yang berhubungan dengan Mengacu pendapat kedua pakar terseb5ut di atas, fungsi wayang ruwatan Sudhamala dan Sapuh Leger sebagai warisan budaya Bali adalah kelahiran anak khususnya yang lahir sebagai anak sukerta/ kotor, hari atau wuku wayang dalam sistem pawukon kalender Bali. Khusus drama ritualnya mengandung tiga asas-asas relegi tentang upacara penyajiannya yakni; (a) Sistem upacara merupakan suatu perwujudan dari relegi, disamping sistem keyakinan dan doktrin; (b) Upacara relegi atau agama dilaksanakan oleh banyak warga pemeluk relegi bersangkutan, yang 
mempunyai fungsi sosial untuk mengintensifkan solidaritas masyarakat Hindu di Bali; dan (c) Fungsi upacara bersaji pada pokoknya, dimana manusia menyajikan sebagian dari seekor binatang sebgai persembahan, untuk mendorong solidaritas dengan dewa atau para dewa. Wayang ruwatan Sudhamala dan Sapuh Leger dianggap sebagai salah satu manifestasi dari usaha legitimasi ritual keagamaan dalam kerangka pengajaran kerohanian (Hindu). Asumsi ini didasarkan atas beberapa alasan yaitu; Pertama, terlaksananya upacara lukatan/ruwatan (penyucian) setelah selesai pergelaran wayang kulit; Kedua, repertoar yang digunakan sebagai dasar cerita/lakon adalah Murwakala, lakon tersebut dikramatkan hingga sekarang oleh masyarakat Hindu Bali. Lakon tersebut mengandung sastra agama (Itihasa) yang bersumber pada lontar Siwagama dan lontar Tantu Pagelaran; dan Ketiga, penggunaan serana upacara/sesajen jumlahnya sangat besar dan jenisnya cukup banyak, rinci, dan rumit. Bentuk-bentuk sesajen terebut mengukuhkan genre wayang ruwatan Sudhamala dan Sapuh Leger sebagai bagian upacara agama, karena dalam pelaksanaan masyarakat Hindu Bali lebih mengedepankan pada penekanan upacara / ritual dari karangka dasar penghayatan agama Hindu yaitu; Tatwa (Filsafat), Susila (Etika) dan upacara (Ritual)

\subsection{Makna Wayang Ruwatan Sudhamala dan Sapuh Leger dalam Masyarakat Hindu Bali}

Lakon Sudhamala dalam lontar Siwagama berawal dari Hyang Siwa menyuruh Dewi Uma ke alam manusia guna mencari obat, walau ini merupakan akal-akalan Hyang Siwa untuk menguji kesetian Dewi Uma sebagai Istrinya. Di alam manusia Dewi Uma melakukan Kama Salah (Manik Sphatika) dengan pengembala sapi, kepulangan beliau ke sorga menjadi titik kesalahan Dewi Uma hingga dikutuk menjadi penghuni kuburan. Wajah yang seram dengan sebutan Dewi Durga, pada akhirnya di bersihkan/Sudhamala oleh Sang Sahdewa. Kembalinya Dewi Uma dalam wujud cantik merupakan simbol penyucian kotoran yang membelenggunya.

Lontar Cepa Kala/Japa Kala dalam lakon Sapuh Leger disebutkan bahwa lahirnya Dewa Kala bermula dari segumpal bola api yang di sebut Manik Sphatika yang artinya sperma yang mengkristal, tiada lain adalah sperma Hyang Siwa jatuh di samudra. Kama yang sepat ditunggu oleh para Dewa di Sorga. Karena kelahirannya lama sekali tidak muncul, seluruh dewata memecahkan dengan senjata mereka masing-masing. Maka muncullah seorang raksasa besar, giginya runcing, rambut gempal, suara membelah akasa serta mata yang nyemporot, semua dewata melarikan diri menjauhinya.

Makna kedua cerita lontar tersebut adalah pertemuan laki dan perempuan dalam memadu kasih tidak pada tempatnya, awal terbentuknya benih janin dalam kandungan seorang istri/ibu. Manik Sphatika tiada lain adalah sperma dari ayah akibat hubungan yang menyimpang. Pertemuan Kama-Jaya dan Kama-Ratih menghasilkan cabang bayi dalam kandungan. Menurut dalang I Made Sidja bahwa setiap adegan wayang dalam lakon Sudhamala dan Sapuh Leger mengandung makna sebuah proses kelahiran bayi beserta perwatakanya. Seperti adegan terakhir lakon Sapuh Leger, terjadi perselisihan Bhatara Kala/Dewa Kala dengan dalang Sambirana, dan berakhir dengan tunduknya Dewa Kala berkat 
kekuatan magis seorang dalang. Makna akhir alur mitos ini adalah upaya keras dalam pendewasaan pribadi dan akhlat manusia. Kiranya dapat disimpulkan bahwa secara psikologis mitos Sudhamala dan Sapuh Leger adalah norma-norma yang menyangkut nilai-nilai etis berhubungan dengan hidup manusia sebagai mahluk pribadi, mahluk alam, mahluk sosial, dan mahluk Tuhan.

\subsection{Filosofis Wayang Ruwatan}

Aspek filosofis wayang ruwatan kalau diamati dari fungsinya, ia mengikuti konsep yang berorientasi temporal, kosmologi dan spritual. Secara temporal pertunjukan wayang Sudhamala dan Sapuh Leger diselenggarakan pada saat-saat tertentu saja yaitu pada hari tertentu menurut kalender/pawukon Bali. Mitologi ritual ruwatan mengharuskan masyarakat umat Hindu Bali percaya bahwa dilarang berpergian pada siang hari (tungai tepet), sore hari (Sandikala), dan tengah malam (Tengah lemeng), karena diyakini bahwa waktu-waktu tersebut adalah waktu transisi yang mengancam keamanan seseorang yang melakukan perjalanan. Tumpek wayang salah satu hari tertentu merupakan tumpukan dari waktu-waktu transisi dan hari itu jatuh pada Sabtu Kajeng Kliwon Wuku Wayang, di mana hari Sabtu merupakan hari terakhir dalam perhitungan Saptawara (Redite/Minggu, Soma/Senin, Anggara/Selasa, Bhuda/Rabu, Wrasphati/Kamis, Sukra/Jumat, Saniscara/Sabtu); Kajeng merupakan hari terakhir dalam Triwara (Pasah, Beteng, dan Kajeng); dan Kliwon menjadi hari terakhir dalam perhitungan Pancawara (Umanis, Paing, Pon, Wage, dan Kliwon). Sedangkan wuku wayang adalah tumpek terakhir dari urutan enam tumpek yang ada dalam siklus kalender Bali ( Tumpek Landep, Tumpek Pengarah, Tumpek Kuningan, Tumpek Krulut, Tumpek Kandang, dan Tumpek Wayang). Dengan demikian dapat disimpulkan bahwa tumpek wayang menjadi hari yang penuh dengan waktuwaktu peralihan, dan oleh karenanya anak-anak yang lahir pada saat ini ditakdirkan menderita karena mengalami gangguan emosi dan menyusahkan orang lain. Untuk melawan hal tersebut, orang Hindu Bali melakukan upacara' penebusan dosa khusus" yang dinamakan ritual ruwatan/lukatan Sapuh Leger, dengan harapan para dewa akan menganugrahkan nasib baik pada anak itu dan menjamin bahwa hari lahir yang tidak baik itu tidak akan berpengaruh buruk pada perkembangan kehidupannya sehari-hari.

Di dalam estetika Hindu dikenal rumusan bahwa suatu hasil seni untuk dapat dkatakan indah dan bermutu, harus memenuhi 6 syarat yang disebut sadangga yaitu: (1) Rupa-bheda, bentuk-bentuk yang digambarkan harus sesuai dengan ide yang dikandungnya; (2) Sadrsya, kesamaan dalam pengelihatan; (3) Pramana, sesuai dengan ukuran yang tepat; (4) Warnika-bhangga, penguraian dan pembikinan warna; (5) Bhawa, suasana dan pancaran rasa; dan (6) Lawanya, keindahan dan daya pesona. Keenam syarat di atas sudah dipenuhi dalam tatanan pertunjukan wayang ruatan. Lakon dapat diketahui dan dihayati makna kefalsafahnya yang mendalam dari setiap cerita atau lakon wayang bersifat klasik tradisional. Lakon wayang ruatan merupakan mitos yang memberikan gambaran, bahwa nilai etika dan moral agar segala tindakan dan prilaku tidak melanggar tata susila atau norma-norma yang berlaku. Dalam naskah ruatan sapuhleger mengandung filosofi sebagai isyarat suatu kelahiran, dikuti oleh 
empat cairan seperti; yeh nyom (air ketuban), rah/getih (darah), lamad/lamas (vermix caceosa) dan ari-ari (plasenta). Keempat unsur atau jasad tersebut dalam kepercayaan masyarakat Bali sering disebut Catur Sanak dengan menyerupai empat saudara. Janin yang ada dalam kandungan mendapat pemeliharaan serta penjagaan dari empat unsur tersebut, seperti: (1) Yeh nyom, adalah merupakan cairan yang melindungi si bayi terhadap sentuhan/getaran-getaran dari luar; (2) Lamas/lamad, adalah lemak yang membungkus jasmani si bayi; (3) Getih/darah, adalah mengedarkan sat makanan, air dan lain-lainnya; (3) Ari-ari, adalah tempat melekatnya tali pusat, penyerap makanan dan lain sebagainya. Keempat unsur cairan tersebut sering di sebut Kanda-Empat empat bagian yang terdiri dari Kanda Pat Rare, Kanda Pat Bhuta, Kanda Pat Dewa, dan Kanda Pat Sari.

Kanda Pat Rare, penetahuan mistik tentang kewajiban manusia melanjutkan keturunan, dari pertemuan Kamajaya-Kamaratih sehingga menghasilkan janin bayi yang disebut Sanghyang Legaprana. Secara simbolis dalam pelaksanaan ari-ari bayi di tanam di depan pintu rumah, setelah dilukat dengan air suci empat saudara ini diberinama baru; Sang Gargha, Sang Maitri, Sang Kurusya dan Sang Pratanjala (Sang Catur Sanak).Kanda Pat Bhuta, penetahuan mistik yang mengasosiasikan wadag manusia (mikrokosmos) laksana wadag jagat raya yang disebut bhuta. Dalam tubuh manusia mempunyai misi mengemban manusia sampai dewasa, seiring bertambah usia/umur maka nama barupun didapat seperti; Anggapati menjadi bhuta Dengen(Utara), Prajaphati menjadi bhuta Kala(Selatan), Bhanaspati menjadi bhuta Preta (Barat), dan Banaspatiraja menjadi bhuta anta(Utara). Kanda Pat Dewa, pengetahuan mistik tentang persemayaman dewa-dewa (Panca Dewata) dalam manusia, dengan mengikut sertakan "saudara empat" dan aksara/hurup suci, seperti; (a) Yeh nyom berwujud Dewa Wisnu dengan aksara Ang bertempat di utara, menempati suku kiwa/kaki kiri; (b) Getih/darah perwujudan Dewa Brahma aksara Bang bertempat di selatan serta menempati suku tengen/ kaki kanan; (c) Ari-ari berwujud Dewa Iswara dengan aksara suci Sang bertempat di timur, serta menempati tangan tengen/tangan kanan; (d) Lamas, perwujudan Dewa Mahadewa, dengan aksara suci Tang, bertempat di barat, serta menempati tangan kiwa/tangan kiri; dan (e) Ditengah persemayaman Dewa Siwa, aksara Ing, serta menempati bagian atma/Jiwatman. Sedangkan Kanda Pat Sari, mencakup ketiga kanda Empat dengan mengambil nama depan orang Bali seperti; (1) Sang Bhuta Anggapati menjadi I Ratu Tangkeb Langit, menguasai sawah, danau, dan binatang; (2) Sang Bhuta Mrajapati menjadi I Ratu Wayan Tebeng, menguasai gunung, Hutan, Kayu, dan Jalan Raya; (3) Sang Bhuta Banaspati menjadi I Ratu Made Jalawung' menguasai pengarangan rumah, dan ladang; (4) Sang Bhuta Banaspatiraja menjadi I Ratu Nyoman Sakti Pengadangan, menguasai kuburan, suangai, jurang, setan, wong samar, taksu, burung, pragina, dalang, balian, usadha, dan kesaktian;(5) Sang Bhuta Dengen menjadi I Ratu Ketut Petung, menguasai pasar, pelangkiran, pengempu Rare, Tukang, undagi, Sangging, dan Tukang Gambelan.

\subsection{Peran Pemerintah dalam Ruatan sebagai Tradisi yang Disakralkan}

Pertunjukan Wayang ruatan khususnya wayang Sapuhleger dipentaskan secara periodic, yaitu tiap-tiap 6 bulan atau 210 hari menurut kalender pawukon 
Bali, tepatnya pada waktu hari/wuku wayang, suadah menjadi tradisi yang begitu kuat berakar pada budaya masyarakat Bali. Dari sifatnya yang religious, magis, dan spiritual. Hari atau Wuku wayang merupakan wuku terakhir dari enam wuku dalam siklus kalendar Bali, dianggap hari yang paling kramat dan disucikan, sehingga hari hari tersebut tidak hanya untuk kelahiran yang leteh/sukerta, namun pada hari itu dirayakan pula sebagai otonan/odalan wayang yang disebut Saniscara kliwon Tumpek Wayang.

Pertunjukan wayang kulit ruatan Sudhamala dan Sapuhleger merupakan ritual yang sangat besar terutama dalam pendanaan/biaya ritual. Dengan dana yang besar menyebabkan banyak kabupaten-kabupaten di Bali menyelenggarakan ruatan masal, dengan tujuan bisa membantu menyucikan orang-orang yang dikatagorikan orang leteh/sukerta. Berdasarkan surve peneliti kemasing-masing tempat ruatan disekitar pulau Bali, ada beberapa kabupaten yang telah melaksanakan ruatan masal diantaranya;

\begin{tabular}{|l|l|l|l|l|l|}
\hline No & Kabupaten & $\begin{array}{l}\text { Th } 2018 \\
\text { Banyaknya }\end{array}$ & $\begin{array}{l}\text { Th 2019 } \\
\text { Banyaknya }\end{array}$ & $\begin{array}{l}\text { Th 2020 } \\
\text { Banyaknya }\end{array}$ & $\begin{array}{l}\text { Th 2021 } \\
\text { Banyaknya }\end{array}$ \\
\hline 1 & $\begin{array}{l}\text { Kabupaten } \\
\text { Badung }\end{array}$ & $\begin{array}{l}\text { Terlaksana } \\
407 \text { orang }\end{array}$ & $\begin{array}{l}\text { Terlaksana } \\
525 \text { orang }\end{array}$ & Covid & Covid \\
\hline 2 & $\begin{array}{l}\text { Kabupaten } \\
\text { Tabanan }\end{array}$ & $\begin{array}{l}\text { Terlaksana } \\
\text { 248 orang }\end{array}$ & $\begin{array}{l}\text { Terlaksana } \\
\text { 267 orang }\end{array}$ & Covid & Covid \\
\hline 3 & $\begin{array}{l}\text { Walikota } \\
\text { Denpasar }\end{array}$ & $\begin{array}{l}\text { Terlaksana } \\
\text { 324 orang }\end{array}$ & $\begin{array}{l}\text { Terlaksana } \\
\text { 301 orang }\end{array}$ & Covid & Covid \\
\hline 4 & $\begin{array}{l}\text { Kabupaten } \\
\text { Gianyar }\end{array}$ & $\begin{array}{l}\text { Terlaksana } \\
\text { 279 orang }\end{array}$ & $\begin{array}{l}\text { Terlaksana } \\
167 \text { orang }\end{array}$ & Covid & Covid \\
\hline
\end{tabular}

\begin{tabular}{|l|l|l|l|l|l|}
\hline 5 & $\begin{array}{l}\text { Kabupaten } \\
\text { klungkung }\end{array}$ & $\begin{array}{l}\text { Terlaksana } \\
\text { 342 orang }\end{array}$ & $\begin{array}{l}\text { Terlaksana } \\
\text { 292 orang }\end{array}$ & Covid & Covid \\
\hline 6 & $\begin{array}{l}\text { Kabupaten } \\
\text { Karangasem }\end{array}$ & $\begin{array}{l}\text { Terlaksana } \\
\text { 501 orang }\end{array}$ & $\begin{array}{l}\text { Terlaksana } \\
\text { 235 orang }\end{array}$ & Covid & Covid \\
\hline 7 & $\begin{array}{l}\text { Kabupeten } \\
\text { Singaraja }\end{array}$ & $\begin{array}{l}\text { Terlaksana } \\
\text { 367 orang }\end{array}$ & $\begin{array}{l}\text { Terlaksana } \\
\text { 237 orang }\end{array}$ & Covid & Covid \\
\hline
\end{tabular}

Data Peneliti/penulis 2018-2021

Pelaksanaan ruatan Sapuhleger masal setiap kabupaten sebagian besar digelar/ dilaksanakan di lapangan umum setempat kecuali, Kabupaten Badung pelaksanaan ruatan di Kantor pemerintahan Bupati Badung.

\section{PENUTUP}

Wayang Sudhamala dan Sapuhleger adalah jenis wayang kulit Bali yang mengandung fungsi dan bermakna sebagai upacara ritual, Ia termasuk sacral dalam konteksnya karena merupakan bagian wali sebuah upacara Hindu Bali dalam lingkungan siklus kehidupan manusia. Bentuk kerangka lakon pengeruwatan yang pelaksanaanya pada siang hari dengan pertunjukan wayang kulit lakon Sudhamala. Wayang ruatan ini sering di Bali disebut wayang lemah/wayang gedog, lakon diambil dari lontar Siwatatwa. Ruatan yang dilaksanakan 
pada malam hari disebut Sapuhleger, khusus dipertunjukan pada kelahiran anak yang lahirnya persis pada hari-hari kramat seperti; Sabtu/Saniscara Kajeng Kliwon Tumpek Wayang. Lakon berasal dari Lontar Siwagama.

Pementasan wayang ruwatan sebagai ritual keagamaan, berfungsi untuk upacara manusa Yajna, ruwatan Sudhamala dan Sapuh Leger merupakan warisan budaya Bali khususnya yang lahir sebagai anak sukerta/ kotor, hari atau wuku wayang dalam sistem pawukon kalender Bali. Drama ritualnya mengandung tiga asas-asas relegi tentang upacara penyajiannya yakni; (a) Sistem upacara merupakan suatu perwujudan dari relegi, disamping sistem keyakinan dan doktrin; (b) Upacara relegi atau agama dilaksanakan oleh banyak warga pemeluk relegi bersangkutan, yang mempunyai fungsi sosial untuk mengintensifkan solidaritas masyarakat Hindu di Bali; dan (c) Fungsi upacara bersaji pada pokoknya, dimana manusia menyajikan sebagian dari seekor binatang sebagai persembahan, untuk mendorong solidaritas dengan dewa atau para dewa. Wayang ruwatan Sudhamala dan Sapuh Leger dianggap sebagai salah satu manifestasi dari usaha legitimasi ritual keagamaan dalam kerangka pengajaran kerohanian (Hindu). Makna akhir alur mitos ruwatan ini adalah sebagai upaya keras dalam pendewasaan pribadi dan akhlat manusia. Kiranya dapat disimpulkan bahwa secara psikologis mitos Sudhamala dan SapuhLeger adalah norma-norma yang menyangkut nilai-nilai etis berhubungan dengan hidup manusia sebagai mahluk pribadi, mahluk alam, mahluk sosial, dan mahluk Tuhan.

Naskah ruatan Sapuhleger mengandung filosofi sebagai isyarat suatu kelahiran, dikuti oleh empat cairan seperti; yeh nyom (air ketuban), rah/getih (darah), lamad/lamas (vermix caceosa) dan ari-ari (plasenta). Keempat unsur atau jasad tersebut dalam kepercayaan masyarakat Bali sering disebut Catur Sanak dengan menyerupai empat saudara. Janin yang ada dalam kandungan mendapat pemeliharaan serta penjagaan dari empat unsur tersebut, seperti: (1) Yeh nyom, (2) Lamas/lamad, (3) Getih/darah, (4) Ari-ari, Keempat unsur cairan tersebut sering di sebut Kanda-Empat empat yang terdiri dari Kanda Pat Rare, Kanda Pat Bhuta, Kanda Pat Dewa, dan Kanda Pat Sari.

Dilihat dari materi/biaya, pertunjukan wayang kulit ruatan Sudhamala dan Sapuhleger merupakan ritual yang sangat besar terutama dalam pendanaan/biaya ritual. Dengan dana yang besar menyebabkan banyak kabupaten-kabupaten di Bali menyelenggarakan ruatan masal, dengan tujuan pemerintah bisa membantu menyucikan orang-orang yang dikatagorikan orang leteh/sukerta.

\section{DAFTAR PUSTAKA}

Bagus, I Gusti Ngurah. 1985. Upacara Ruatan di Bali menurut konsepsi Orang Jawa. Sudarsono (ed). Yogyakarta: Depertemen Pendidikan dan Kebudayaan.

Bandem, I Made. (1994). Mengembangkan Lingkungan Sosial yang Mendukung Wayang. Mudra: Jurnal Seni Budaya.

Bandem, I Made. 1988. Transformasi Kesenian dalam Pelestarian Nilai-Nilai Budaya Bali. dalam Atmaja (ed). Denpasar: CV Kayumas. 
Haryanto, S. 1992. Bayang-Bayang Adhiluhung, Filsafat, Simbol dan Mistik dalam Wayang. Semarang: Effhar dan Dahara Prize.

Hooykaas, C. 1973. Kama and Kala, Material For The Study Of Shadow Theater In Bali. Amsterdam: Nort-Hollend Publising Company.

Hooykaas, C. 1973. Lontar Kala Purana. Amsterdam: North-Holland Publishing Company.

Kamajaya, H Karkono et al. 1992. Ruwatan Murwakala: Suatu Pedoman. Duta Wacana University Press.

Lontar Tatwa Japakala. 1988. Pusat Dokumentasi Kebudayaan Daerah Bali.

Lontar Kala Tatwa. 1986. Pusat Dukumentasi Kebudayaan Bali.

Lontar Cepe Kala, K. 504, Turunan lontar Gedung Kirtya (Singaraja).

Lontar Kekawin Sanghyang Kala, Turunan Lontar Kirtya (Singaraja).

Lontar Kidung Sapuhleger. 1974. Koleksi Gedong Kirtya-LISTIBYA Daerah Bali.

Mulyono, Sri. 1979. Simbolisme dan Mistikisme dalam Wayang: Sebuah Tinjauan Filosofis. Jakarta: PT Gunung Agung.

Putra, Ny I Gusti Agung Mas. 1987. Upacara Manusa Yadnya. Jakarta.

Rota, Ketut. 1990. Retorika sebagai Ragam Bahasa Panggung dalam Seni Pertunjukan Wayang Kulit Bali. Laporan Penelitian STSI Denpasar.

Rota, Ketut. 1992. Dharma Pewayangan Kulit Bali; Study Eksploratif tentang Identitas dan Fungsinya. Laporan Penelitian STSI Denpasar.

Soetarno. 1995. Ruwatan di Daerah Surakarta. Surakarta: CV Cendrawasih.

Sudha, Ida Bagus Raka. 1980. Manusa Yadnya dalam Hubungannya dengan Wayang Sapuhleger. (Skripsi). Institut Hindu Dharma.

Wiryamartana, I Kuntara. 1977. Permenungan Tentang Lakon Ruwat, Dalang Karurungan dari Sudut-Sudut Filsafat: Sebuah Bungan Rampai. Yogyakarta: Kanisius.

Wicaksana, I Dewa. (1996). Wayang Lemah Refleksi Nilai-Nilai Budaya dan Agama Hindu Masyarakat Bali. Mudra: Jurnal Seni Budaya.

Wicaksana, I Dewa. 2007. Wayang Sapuhleger, Fungsi dan Makna dalam Masyarakat Bali. (Disertasi). Pascasarjana ISI Denpasar. 